and does not interfere with any aspect of the baby's care.

The amplitude of the signal is a qualitative reflection of change in intrathoracic pressure and is not a measure of tidal volume. Quantitative timing measurements can be made and phase relations between spontaneous respiration and ventilation studied. The capsule can be used to detect the baby breathing out of phase with the ventilator, even when clinical observation would not suggest this. This pattern of interaction can reduce the efficacy of ventilation and increases the risk of pneumothorax. ${ }^{2}$

This method should prove to be a useful tool in ventilation research and in neonatal clinical practice.

We thank Professor J A Davis. Dr N R C Roberton, and Dr G Gandy for their encouragement and advice. Sr J Pool for making the oesophageal balloons, and the nursing staff of the neonatal unit at the Rosie Maternity Hospital. This work is supported by the University of Cambridge Baby Research Fund.

\section{References}

1 Greenough A, Morley CJ, Davis JA. Respiratory reflexes in ventilated premature babies. Early Hum Dev 1983;8:65-75.

2 Greenough A, Morley CJ, Wood S, Davis JA. Pancuronium prevents pneumothorax in ventilated premature babies who actively expire against positive pressure inflation. Lancet $1984: i: 1-3$.

${ }^{3}$ Wright BM. An abdominal respiration detector. J Physiol (Lond) 1977;271:11-2.

4 Wright BM, Callan K, eds. Proceedings of the 3rd international symposium on ambulatory monitoring. London: Academic Press, 1980:329-34.

Correspondence to $\operatorname{Dr} M$ South, Department of Paediatrics, University of Cambridge, Level E8, Addenbrooke's Hospital, Cambridge CB2 2QQ.

Received 26 November 1985

\title{
Home care team in accident and emergency
}

\author{
E GLUCKSMAN, S S TACHAKRA, S PIGGOTT, AND H LEA
}

Central Middlesex Hospital, London

SUMMARY We describe experience with a community paediatric service designed to provide more convenient follow up for children and their families and to reduce the number of children returning unnecessarily to the accident and emergency department.

Every year one in six children are likely to attend accident and emergency departments, making up roughly $20 \%$ of the new attendances to departments in England and Wales. ${ }^{1}$ It has been suggested repeatedly that accident and emergency departents may not be the most satisfactory places for seeing and treating sick children. ${ }^{2}$ Nevertheless, many families use the accident and emergency department, and commonly as an alternative to the general practitioner's surgery. ${ }^{3}$ Although it may be difficult to alter substantially the pattern of new attendances by children, it may be practical to identify children who need follow up after the initial visit but who need not return to accident and emergency departments.

\section{Patients and methods}

In 1981 the role of an existing paediatric home care team was extended to follow up selected children attending the accident and emergency department. Children who might not require hospital facilities for follow up included those with: medical problems for example, vomiting or diarrhoea; simple sutured lacerations; minor burns; and other soft tissue injuries where dressing changes were required - for example, dog bites. Children under 12 who lived in the Brent Health District were eligible for referral and the service was available seven days a week and provided by three paediatric sisters, all with SRN RSCN qualifications. Medical responsibility remained with the accident and emergency staff, and if problems arose nurses referred children to the department.

If the child's injury or illness was suitable for referral the accompanying parent or guardian was given the choice of a community visit or reattendance to the accident and emergency department. As an indication of the usefulness of the service a brief questionnaire was given to families in which an adult understood English. Visits and treatments were carried out at school, nursery, childminder, or home, whichever was most suitable. Parents were given a card advising them to call if worried.

\section{Results}

Between 1 December 1982 and 30 November 1983 there were a total of 36971 new patient attendances

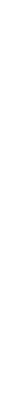


Table Outcome of community paediatric service referrals

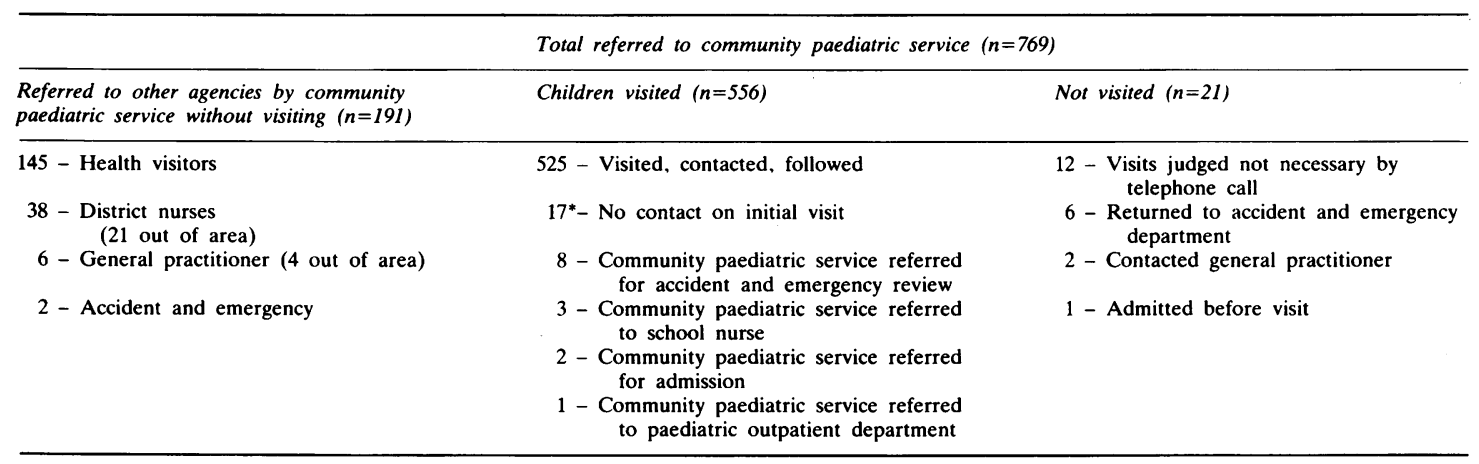

*If no contact was made on the initial visit, a card was left at home asking the parents to contact the hospital.

at the accident and emergency department, of which $6775(18 \%)$ were children. Of these, 2484 were referred for specific outpatient follow up, and 808 $(33 \%)$ were offered the community paediatric service. Altogether, $769(95 \%)$ opted for the community service, and $727(95 \%)$ of the referrals to the community paediatric service were made after the initial visit to the accident and emergency department.

Visits by community paediatric service nurses totalled 1271 (average two per patient). Thus up to this number of reattendances by children were diverted from accident and emergency. Of the 556 children seen, $351(63 \%)$ received a single visit, and the maximum number of visits per referral was five. Forty per cent of the children were referred for follow up of minor medical problems, $30 \%$ for removal of sutures, and $30 \%$ for soft tissue injuries, including burns. The Table depicts the outcome of referrals to the community paediatric service. Overall, 556 children were visited and very few (18 out of $769(2 \cdot 3 \%))$ were judged to need reassessment in or admission to hospital because their condition changed.

\section{Questionnaire}

Altogether, 335 questionnaires were given $(60 \%$ of those visited), and 224 (67\%) were returned completed. Ninety nine per cent of the responses were favourable, and all indicated that they would choose this form of follow up again. Although no reason for accepting or declining the offer was required, reasons in favour of a community visit included: waiting times in accident and emergency, distance to hospital, cost of public transport, siblings, and preference for a nurse specially trained in child health. No comments were received to suggest a decision was made considering the sights and sounds of adult emergencies. Of the 39 parents who declined community paediatric service, most preferred to choose the time of their reattendance, children were older, or the family lived close to the hospital. It seemed no parents declined the service because they objected to nurse rather than doctor assessment, and in fact the special skills of a children's nurse were greatly appreciated.

\section{Discussion}

Paediatric home care teams have existed since 1948. ${ }^{4}$ Some of these schemes ${ }^{4}$ accept referrals from accident and emergency departments, but as far as we are aware no other community paediatric service exists in this country linked to the accident and emergency department.

Progress to provide more suitable facilities for children in accident and emergency departments has been slow, and a recent survey by the British Paediatric Association concluded that there was room for 'a great deal of improvement': $75 \%$ of the responding accident and emergency departments did not have a separate waiting room for children, it was the exception that staff were trained in the care of sick children, and more often than not there was no liaison health visitor attached to the department. ${ }^{5}$

General practitioners, practice attached and district nurses, and health visitors were sent details of the service. No adverse comments were received from family doctors, and no children seen by the community paediatric service were referred back to hospital by general practitioners. Although many of the children referred to the community paediatric service could have been followed by health centre staff, some of the reasons for preferring a home visit from the service apply to general practice as well as to 
accident and emergency departments, - that is, easier if other young children were at home, less disruptive if child at school. Duplication of services provided by practice attached nurses was a consideration, but only $25 \%$ of local practices have such a nurse, they do not go into schools, they generally do not see the handicapped, and most have little specialised paediatric training.

The service could have been interpreted by generalist district nurses as causing them to lose out on paediatric experience, but no dissatisfaction was expressed to us. Similarly, accident and emergency staff might have felt deprived of practical paediatric work. However, staff thought that there were sufficient numbers of children attending accident and emergency departments to provide this experience and that they were able to care more effectively for new patients and those requiring hospital follow up. During the period reported no additional case of frank non-accidental injury was detected by the scheme, but there seemed to be ample opportunity and scope for practical help regarding health education and secondary accident prevention.

The overlap between health visitors and the community paediatric service was potentially great, but referrals were redirected accordingly, and the existence of the service improved the casualty medical staff's understanding of the health visitor's role.

Paediatric home care team schemes that report costs suggest that they are economically viable. ${ }^{4}$ In our scheme the community paediatric service sisters were already employed to visit children at home, and no additional staff were required for this accident and emergency based service. No appreciable extra travel costs were incurred, and as nursing costs represent the most expensive fraction of the cost of an attendance at an accident and emergency department, ${ }^{6}$ community care of this kind seems to be cost effective. The service has been assessed as being beneficial by providers, it is appreciated by users, and continues as a valuable community extension of combined accident and emergency and paediatric nursing care. This home care scheme should be considered as one component of a health care system accommodating the special needs of children and their families.

We are grateful to the staff and patients of the accident and emergency department at Central Middlesex Hospital who participated in the development of this service and to Dr B Taylor and Miss S Smith for help with the manuscript.

\section{References}

1 Wells N. Accidents in childhood. London: Office of Health Economics, 1981.

2 Platt H. Accident and emergency services. Report of the subcommittee. Standing Medical Advisory Committee. London: HMSO, 1982.

3 Acheson ED. Primary health care in inner London. Report of the Study Group, London Health Planning Consortium. London: DHSS, 1981.

4 Bergman AB, Shrand H, Oppe TE. A paediatric home care programme in London-ten years experience. Pediatrics 1965; 36:314-21.

5 Children's attendences at accident and emergency departments. London: Joint Accident Committee of the BPA and BAPS (Document 36), 1984.

6 Department of Health and Social Security. DHSS performance indicators, regional summary for 1981, South East Thames. London: DHSS, 1983.

Correspondence to Dr E Glucksman, King's College Hospital, Demark Hill, London SE5 9RS.

Received 20 November 1985

\title{
Height at diagnosis in acute lymphocytic leukaemia
}

\author{
F BESSHO
}

Department of Pediatrics, University of Tokyo, Japan

SUMmary The heights of children with acute lymphocytic leukaemia were compared with controls matched for age, sex, and period. In contrast to a previous report the subject patients were not taller than their matched controls.

Various kinds of growth factors have been impli- cated to have important roles in carcinogenesis. ${ }^{1}$ It has been suggested that growth hormone may be involved in the development of acute lymphocytic leukaemia. ${ }^{2}$ It has also been reported that children with acute lymphocytic leukaemia are taller than the normal population. ${ }^{3}$ To validate this finding pretreatment heights of children with acute lymphocytic leukaemia were compared with those of matched controls. 